\title{
Tìm hiểu về chữ nghiên cứu 研究
}

\author{
Vương Quân Hoàng
}

Ngày 17-12-2021

Chữ nghiên cứu đọc lên hẳn nhiên đã có cảm nhận là âm Hán-Việt. Ngoài ra, do nhận thấy đa phần các ý niệm học thuật cũng như ngôn từ của học giới từ xa xưa đã hay sử dụng những từ có nguồn gốc chữ Hán, nên tôi tò mò tìm hiểu về chữ "nghiên cứu", để xem nó có hình dạng cấu tạo và chứa đựng ý nghĩa gì.

Chữ Hán hiện đại nó được viết như sau: 研究 (phiên âm: yán jïü ${ }^{[1]}$ )

Chữ "nghiên cứu" trong tiếng Việt được hiểu là việc nghiền ngẫm tìm tòi đến chỗ sâu xa (của sự vật, hiện tượng, thế giới, v.v..). Tất nhiên đây là cách nói ngắn gọn, kiểu giải nghĩa từ điển với ý nghĩa thông dụng. Còn học giới có thể tùy từng ngành, hay theo trường phái, mà sẽ có cách hiểu khác đi trên phương diện ngữ nghĩa.

Tuy vậy, dù có khác nhau thế nào thì về cơ bản, khái niệm nghiên cứu cũng chứa đựng những ý nghĩa chính:

1. Thâm nhập, dùi mài, và xem xét đến tận cùng nghĩa lí.

2. Bàn bạc, thảo luận, tranh biện.

3. Tìm hiểu sâu sắc, kỹ càng.

(Điều thú vị chính là ta đang "nghiên cứu" về chính cái chữ "nghiên cứu", dù là ở mức độ rất sơ đẳng.)

Bây giờ, thử nhìn vào bên trong cấu tạo của cả hai chữ, và cấu tạo của từng chữ hợp thành. Chúng ta thấy xuất hiện các thành phần sau.

\section{Trước tiên là chữ "nghiên" 研}

Chữ này được hợp thành bởi 2 phần, nửa đầu là chữ thạch (石) mà thể dạng Kim văn trông như hình dưới đây: ${ }^{1}$

\footnotetext{
${ }^{1}$ Kim văn: Kim văn (金文) hay còn gọi là minh văn (銘文) hay chung đỉnh văn (钟鼎文), là loại văn tự được khắc hoặc đúc trên đồ đồng, kế thừa giáp cốt văn, xuất hiện cuối đời nhà Thương, thịnh hành vào đời Tây Chu. Nội dung thường liên quan mật thiết đến cuộc sống tầng lớp thống trị (tế lễ, sắc lệnh, việc chiến tranh, săn bắn...). Kim văn trên Mao công đỉnh thời Chu Tuyên Vương là đại diện cho kim văn. Từ Tây Chu trở về sau, kim văn được sử dụng rộng rãi. Người ta tìm được 3005 chữ kim văn, đã đọc được 1804 chữ, nhiều hơn giáp cốt vắn một chút. Do thời kì Thương Chu rất thịnh hành đồ đồng, mà trong đó chung (chuông) và đỉnh (vạc) là những nhạc khí, lễ khí tiêu biểu nên kim văn còn có tên gọi là chung đỉnh văn. ${ }^{[2]}$
} 


\section{$\sqrt{\theta}$}

Nó có nghĩa nổi bật và thông dụng nhất là "đá".

Và chữ thứ hai là "khai" (开), vốn có lối viết Chiến Quốc văn tự 開. Chữ này có ý nghĩa phổ biến nhất là mở (khai thông, khai quốc công thần), và cả nở (hoa nở) như trong bài Cáo tật thị chúng của Mãn Giác Thiền Sư:

\section{春去百花落，}

\section{春到百花開。}

Xuân khứ bách hoa lạc,

Xuân đáo bách hoa khai.2

Chữ "khai" có kiểu viết Chiến Quốc văn tự rất đẹp (trong hình dưới đây).

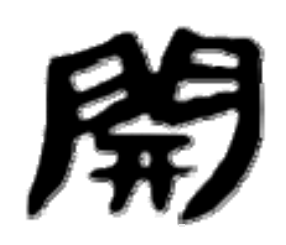

Tôi nhận thấy việc ghép này có thể mang hai ý nghĩa sau, hoặc cả hai. Thứ nhất là nghĩa dễ hiểu: khai mở xuyên qua đá (thứ rất cứng, khó khăn, vất vả). Thứ hai dùng thứ cứng như đá để mở lối (giả sử đó là "ý chí sắt đá", như ta vẫn hay nói trong tiếng Việt). Và nhìn đi nhìn lại thì hình như gộp cả hai ý nghĩa này cùng lúc cũng không gây ra xung đột gì với nhau.

Khi ghép cả hai lại thành chữ "nghiên" thì nó có ý nghĩa "nghiền, mài, tìm tòi". Nhà nghiên cứu Hoàng Tuấn Công qua trao đổi cũng nêu rõ chữ nghiên này trực tiếp liên quan tới ý nghĩa "nghiên mực", nghiền và mài mực.

Sự dịch qua chuyển lại của ngữ nghĩa liên quan khiến tôi có cảm giác còn thích thú hơn vì khi suy nghĩ gì kỹ lưỡng, cân nhắc nhiều lắm, thì cũng hay gọi là "nghiền ngẫm".

Như thế, chữ "nghiên" này được hiểu là sự tìm tòi kỹ lưỡng, một công việc khó khăn như phá đá mở núi (khai sơn phá thạch), có thể phải có vũ khí suy tư, ý chí vững vàng như đá để giúp phá toang bóng đêm (sự ngu tối?!). Và nó đòi hỏi nghiền ngẫm, giùi mài với nghiệp bút nghiên (viết lách).

\footnotetext{
${ }^{2}$ Nghĩa là: Xuân qua trăm hoa rụng / Xuân đến trăm hoa nở.
} 


\section{Tiếp đến là chữ "cứu" 究}

Phần giải thích cấu tạo chữ "cứu" (究) này được cung cấp bởi nhà nghiên cứu Hoàng Tuấn Công qua trao đổi trực tiếp.

Chữ này có cấu tạo hai phần, sắp trật tự trên và dưới (khác với chữ "nghiên" 研, ghép ngang trái-phải). Ở phía trên là chữ "huyệt" (穴), có ý nghĩa là cái hang, hố. Chữ viết kiểu Chiến quốc văn tự của nó rất đẹp:

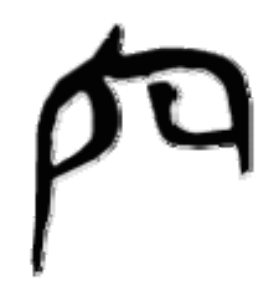

Và phía dưới là chữ "cửu" (九), mang nghĩa phổ biến là số 9, lớn, tận cùng (ví dụ, sâu thăm thẳm hay cao vời vợi). Trong hình dưới là cách viết theo Giáp cốt văn. ${ }^{3}$

\section{そ}

Anh Hoàng Tuấn Công phân tích cho thấy rằng với chữ "cứu" thì chứa đựng cả hình, âm và nghĩa. Nghĩa trở nên rõ hơn khi được ghép lại. Sự sắp đặt này ám chỉ sự đào sâu tới tận cùng, suy xét hết sức tỉ mỉ, rốt ráo. Ngay trong tiếng Việt hiện nay, chữ "cứu" cũng còn hay thấy xuất hiện trong những từ khác có liên quan gần gũi tới công việc nghiên cứu, chẳng hạn như từ "khảo cứu" (考究).

\section{Tới lúc ghép hai chữ lại}

\footnotetext{
${ }^{3}$ Giáp cốt văn (甲骨文) là hệ thống chữ viết tương đối hoàn chỉnh, được phát triển và sử dụng ở Trung Quốc, vào cuối đời Thương (thế kỷ 14-11 TCN), dùng để ghi chép lại nội dung chiêm bốc (văn) của Hoàng thất lên trên yếm rùa (giáp) hoặc xương thú (cốt). Sau khi lật đổ nhà Thương, nhà Chu vẫn tiếp tục sử dụng thể chữ này. Nó được xem là thể chữ cổ xưa nhất, nguồn gốc hình thành chữ Hán hiện đại. Giáp cốt văn được phát hiện tại làng Tiểu Đốn, huyện An Dương, tỉnh Hà Nam, Trung Quốc, niên đại cách đây khoảng 3000 năm, gồm hai loại giáp văn và cốt văn. Giáp văn được khắc trên yếm của rùa, một số ít được khắc trên mai, cốt văn được khắc trên xương trâu. Năm Quang Tự thứ 24 triều nhà Thanh (năm 1898), một số nông dân phát hiện ra những mảnh xương thú khắc văn tự, nhưng tưởng là "long cốt" có thể chữa bệnh nên đã bán cho các hiệu thuốc. Nhà kim thạch học Trung Quốc Vương Ý Vinh và học trò là Triệu Quân vô tình phát hiện ra trên những "long cốt" đó là một loại văn tự cổ. Qua khảo sát phát hiện ra nơi phát hiện được chính là kinh đô cũ của nhà Ân (xem [3]).
} 


\section{研究}

Sau hai phần bóc tách ý nghĩa ở trên, ta sẽ tiếp cận với một ý niệm về nghiên cứu sâu sắc hơn hẳn so với khi nghĩ thoáng qua. Ý nghĩa đó chính là một công việc, hoạt động tìm tòi, suy nghĩ về thế giới, hiện tượng sự vật. Công việc này khó khăn, cân ý chí để vượt qua những thách thức, để có thể tìm đến độ sâu tận cùng, tỉ mỉ, rốt ráo nhất. Kết cục của công việc này có thể chứa đựng cả ý nghĩa cứu cánh.

Rõ ràng, ý nghĩa về sự sẵn sàng vượt khó, mức độ bền bỉ, đào xới, tỉ mỉ, v.v.. là những tính cách đòi hỏi ở công việc nghiên cứu, như chúng ta vẫn biết. Ý nghĩa này khá gần gũi với khuôn khổ nhận thức "3D creativity" [4]. Rõ ràng trên nhiều khía cạnh, chữ nghiên cứu như vừa phân tích rất tương đồng với ý nghĩa research (Anh) hay recherche (Pháp).

Cuối cùng, trước khi chấm dứt việc luận về chữ nghiên cứu, còn một điểm lý thú cần phải nói nốt: Thế nào thì được gọi là "rốt ráo"?

Trong cuộc sống bình thường, nói tới chữ này thì ta hình dung là làm tới hoàn thành thì mới dừng lại. Ví dụ, ta đóng một chiếc ghế, hay nấu một bữa cơm, thì chiếc ghế phải xong sử dụng được, và bữa cớm phải hoàn thành, sẵn sàng mời mọi người ăn. Thế là rốt ráo. Nhưng trong nghiên cứu thì khác. Sâu rồi lại sâu nữa, cao rồi sẽ còn cao hơn nữa, như sự tìm hiểu thế giới vi mô của vật chất, hay sự vươn ra tìm hiểu sự bao la của vũ trụ, v.v..

Quả là rất khó để biết ở đâu là tận cùng, rốt ráo. Vì thế, một phẩm chất quan trọng (cũng là kết quả) là buộc phải luôn tò mò để tìm kiếm và phát hiện. Nói về người phá đá mở núi, không hiếm khi người ta bắt gặp đá quý. Điều này cũng tương tự với những người đào sâu và phát hiện thây kim cương. Với kỷ luật lao động ấy, những người thợ tận tâm ắt sẽ bắt gặp thứ quý hiếm ở nơi hoàn toàn không tính đến, và với giá trị khó mà biết trước, vào lúc chắng thể đoán định. Điều này cũng thường xảy ra trong các phát hiện nghiên cứu khoa học, với tên gọi serendipity ${ }^{[5]}$.

\section{Ý tại ngôn ngoại}

Để thay cho lời kết, xin mượn lối nói ý tại ngôn ngoại (意在言外). Chữ "nghiên cứu" luận tưởng là đã đến cùng, tận, nhưng vẫn chưa phải. Bao trùm lên các thành phần cấu tạo hẳn là gì đó lớn vượt lên phép cộng các thành phần. Thử mạo muội trình bày như sau.

Thứ nhất, đã khai mở, chấp nhận gian truân, thì đi tiếp, bước tiếp. Sâu, sâu đến tận cùng. Cao, cao tới trời xanh. Tới tận cùng cũng là nơi đất trời giao hòa. Chẳng phải vì lẽ này mà rồi Gödel, Escher và Bach cũng gặp nhau trong tác phẩm trứ danh của Hofstadter ${ }^{[6]}$ hay sao? 
Thứ hai, công việc nghiên cứu thực thụ có tính chất mở đường, dẫn lối. Hiển nhiên cái tính chất ây sẽ hàm chứa khó khăn, thử thách, thất bại. Chẳng phải thế mà tận, cùng có thể hình dung bên ngoài ý nghĩa thông thường là khó khăn tới cùng cực, để có lúc đạt được khám phá cao đẹp vời vợi hay sao? Hay nói như đại văn hào Lỗ Tấn: "Kì thực trên mặt đất này làm gì có đường. Người ta đi mãi thì thành đường đấy thôi". Và như ta cũng biết, chữ "khai đạo" (開導) chính là mang ý nghĩa mở lối.

Những kiến giải nói trên hoàn toàn dựa trên suy nghĩ của cá nhân tôi. Do hiểu biết có hạn, hoàn toàn có thể có những sai sót hay nhầm lẫn. Vì thế, mặc dù nhận được sự chỉ bảo, phân tích của anh Hoàng Tuấn Công, nếu có bất kỳ sai sót gì thì đều thuộc về trách nhiệm cá nhân mà thôi. Nhưng ngẫm thấy sự thú vị sâu xa, nên tôi cứ mạnh dạn ghi lại, mong sao được các cao nhân chỉ giáo thêm để được đại khai nhãn giới. ${ }^{4}$

* Lời cảm ơn: Tôi xin chân thành cảm ơn phân tích rất chu đáo, rõ ràng, cũng như góp ý vừa bổ ích vừa lý thú của anh Hoàng Tuấn Công, nhất là với chữ "cứu". Nhà nghiên cứu Hoàng Tuấn Công đã xuất bản một cuốn khảo cứu ngôn ngữ rất giá trị năm 2017 [7].

\section{Tài liệu tham khảo:}

[1] Hanzii. (n.d.). 研究. https://hanzii.net/search/word/研究

[2] Wikipedia. (n.d.) Kim văn. https://vi.wikipedia.org/wiki/Kim văn

[3] Wikipedia. (n.d.). Giáp cốt văn. https://vi.wikipedia.org/wiki/Giáp cốt văn

[4] Vuong, Q. H., \& Napier, N. K. (2014). Making creativity: the value of multiple filters in the innovation process. International Journal of Transitions and Innovation Systems, 3(4), 294-327.

[5] Napier, N. K., \& Vuong, Q. H. (2013). Serendipity as a strategic advantage?. In: Wilkinson (ed.) Strategic Management in the 21st Century (pp. 175-199). Westport, CT: Praeger.

[6] Hofstadter, D. R. (1979). Gödel, Escher, Bach: An Eternal Golden Braid. New York, NY: Basic Books.

[7] Công, H. T. (2017). Từ điển tiếng Việt của Giáo sư Nguyễn Lân: Phê binh và khảo cứu. NXB Hội Nhà văn.

\footnotetext{
${ }^{4}$ 大開眼界
} 